See Article page 77

\section{Commentary: Close it tight, so you can be sure it is open!}

\author{
Yaron D. Barac, MD, PhD
}

In this issue of the Journal, Balasubramanian and Bhama ${ }^{1}$ describe a novel method for an old problem. How do we keep the sternum open after left ventricular assist device (LVAD) implantation or cardiac transplantation? Whereas the methods used thus far have mostly been improvisations, Balasubramanian and Bhama ${ }^{1}$ suggest a method that is not only reproducible but can also ensure a stable distance between the edges of the open sternum.

The number of LVAD being implanted all around the globe is on the rise, and thus more patients are expected to come into surgery with some degree of right ventricular dysfunction that may require leaving the sternum open after LVAD implantation. Similarly, marginal hearts are being used in increasing numbers, some perhaps even after an organ care system or donation after circulatory death protocol, and again the need for an open chest after transplant may arise. ${ }^{2,3}$

The current methods for keeping the sternum open rely on surgeon improvisations that span from just closing the skin without using wires to approximate the sternum, which relives the intrathoracic pressure but keeps the sternum minimally open, to a method that uses plastic syringe struts to spread the sternum more widely and a nonbiologic barrier (Esmarch) for replacing the skin closure. Although these methods have been used by many all around the world, they are not reproduceable, are not sustainable, and require syringe manipulation and adjustments that make them time

From the Division of Cardiovascular and Thoracic Surgery, Rabin Medical Center, Petach-Tikva, Israel; and the Sackler Faculty of Medicine, Tel Aviv University, Tel Aviv, Israel.

Disclosures: The author reported no conflicts of interest.

The Journal policy requires editors and reviewers to disclose conflicts of interest and to decline handling or reviewing manuscripts for which they may have a conflict of interest. The editors and reviewers of this article have no conflicts of interest.

Received for publication Feb 6, 2020; revisions received Feb 6, 2020; accepted for publication Feb 20, 2020; available ahead of print March 5, 2020.

Address for reprints: Yaron D. Barac, MD, PhD, The Division of Cardiovascular and Thoracic Surgery, Rabin Medical Center, Petach-Tikva, Israel, Sackler Faculty of Medicine, Tel Aviv University, Tel Aviv, Israel (E-mail: yaronbar@clalit.org.il). JTCVS Techniques 2020;2:82-3

2666-2507

Copyright $@ 2020$ The Authors. Published by Elsevier Inc. on behalf of The American Association for Thoracic Surgery. This is an open access article under the CC BY-NCND license (http://creativecommons.org/licenses/by-nc-nd/4.0/).

https://doi.org/10.1016/j.xjtc.2020.02.026

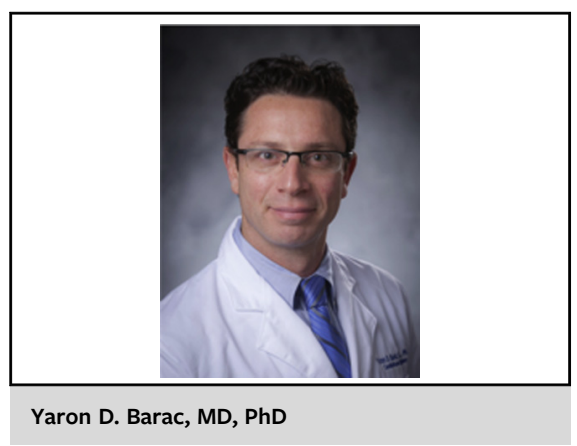

CENTRAL MESSAGE

Leaving the chest open after left ventricular assist device implan-

tation or cardiac transplantation

can be performed with a tech-

nique that is reproduceable and

sustainable without

improvisation.

consuming in the operating room once the decision to leave the chest open has been taken. Newer and more reliable methods are being investigated. ${ }^{4}$

Balasubramanian and Bhama ${ }^{1}$ describe the use of a commercially available tool, an orthopedic plate (Synthes GMBH, Oberdorf, Switzerland) that is secured to the sternum with a wire. As the plate has numerous holes, the surgeon can set the exact distance between the sternal edges. Furthermore; Balasubramanian and $\mathrm{Bhama}^{1}$ also suggest an approach to protect the right ventricle from the plate and the sternum (to prevent potential bleeding) with Gelfoam (Pharmacia and Upjohn Co, Kalamazoo, Mich), followed by skin approximation as the biologic barrier. They describe their experience in 29 patients with LVAD implantation and heart transplant who were treated either with this method or just with skin closure (without the plate); none of the patients had wound infection, and all chests were closed later on in the operating room.

That being said, one should take under consideration the limitations of this small cohort and study. Balasubramanian and Bhama ${ }^{1}$ did not compare the time for chest closure, intensive care unit stay, need for intra-aortic balloon pump or inotropes, or ventilation days. The efficacy of this technique in terms of inducing right ventricular recovery was thus not evaluated.

To summarize, Balasubramanian and Bhama ${ }^{1}$ are to be congratulated for describing and using this technique. Its 
main advantage is the fact that it can be reproducible easily with an instrument that can be found in operating rooms all around the world, with no need for intraoperative improvisation. Furthermore, it assures the surgeon of a specific stable distance between the sternum edges that can be adjusted once the plate has been installed, and the surgeon can be sure that the sternum will remain open exactly as desired.

Importantly, this technique has not been found favorable thus far in terms of inducing or enabling better right ventricular recovery. It can, however, be used as an easy and reliable method for closing the chest tight—so you can be sure that it will stay open!

\section{References}

1. Balasubramanian V, Bhama JK. Technique for "open sternal" chest closure in patients with assist devices and transplant recipients. J Thorac Cardiovasc Surg Tech. 2020;2:77-9.

2. Khush KK, Cherikh WS, Chambers DC, Goldfarb S, Hayes D Jr Kucheryavaya AY, et al; International Society for Heart and Lung Transplantation. The International Thoracic Organ Transplant Registry of the International Society for Heart and Lung Transplantation: thirty-fifth adult heart transplantation report-2018; focus theme: multiorgan transplantation. J Heart Lung Transplant. 2018;37:1155-68.

3. Kirklin JK, Pagani FD, Kormos RL, Stevenson LW, Blume ED, Myers SL, et al Eighth annual INTERMACS report: special focus on framing the impact of adverse events. J Heart Lung Transplant. 2017;36:1080-6.

4. Tanaka Y, Miyamoto T, Naito Y, Yoshitake S, Sasahara A, Miyaji K. Sternal semiclosure using a bioresorbable osteosynthesis device: a new method for delayed sternal closure. Surg Today. 2018;48:748-55. 